\title{
Enhancing the Role of Educational Services of Higher Education System in the Competitive Specialists Training for Industry
}

\author{
Olga Kuznetsova ${ }^{1}$, Svetlana Kuznetsova ${ }^{1}$, Egor Yumaev $^{1}$, Vladimir Kuznetsov ${ }^{1,}$ and Inna \\ Plotnikova ${ }^{2}$ \\ ${ }^{1}$ Omsk State Technical University, 644050, Omsk, Russia \\ ${ }^{2}$ Tomsk Polytechnic University, 634050, Tomsk, Russia
}

\begin{abstract}
The paper shows determination of educational services effect of higher education system to the competitive specialists training for the industry. Universities should focus their efforts on the development of innovative scientific and educational environment of the global level if they want to supply modern industry with highly qualified specialists. Despite the good results achieved in training for industry, universities should always be a step ahead in enhancing the quality of educational services. According to the findings options for professional trainings are offered; also the regional specialized educational resources launch is suggested.
\end{abstract}

\section{Introduction}

In accordance with the human capital assets theory, investments into higher education are paying off in the form of work, resulting in the labor market [1]. However, in our opinion, not investments as they are will get the job done, but the so-called "right" investments into higher education: when the institution is able to provide educational services at a high level.

In today's world, universities must respond flexibly to the rapid development of technology, the emergence of new industrial enterprises, increasing complexity of production processes [2-4]. Great attention should be given to equipping of university laboratories with modern equipment $[5,6]$.

It is not an exaggeration to say that the quality of education determines the future of the industry and competitive perspective of the economy as a whole. To do this, the effectiveness of the higher education system should be improved, as well as the formation of innovative world-class universities network.

In the context of global competition tightening in the educational services market universities need to look for new opportunities to increase awareness of their brands, to develop a variety of directions, among them renovation of educational services for students has primary importance [7]. Reliable and positive reputation becomes a critical factor in the students' attraction to higher education. This trend has been intensified in the context of

*Corresponding author: mivladirvvk@rambler.ru 
globalization, as universities compete with each other not only for the students of the country, but also for foreign ones [8].

Thus, the basis of highly-qualified sought-after in modern industrial enterprises specialists training improves the educational services quality. New opportunities should be searched for to improve the educational process with the purpose of staff training with the current set of competencies.

\section{Analysis}

Studies of foreign scientists show close connection of the University attraction and its brand recognition level [9]. At the same time, if the University takes care of its own brand, it needs a sustainable development program [10]. Its central element is the focus on attracting the best students to develop dynamic creative scientific atmosphere, fair competition, to raise the educational level in the institution.

Much attention in the economy of the developed countries is paid to revolutionizing educational space. The traditional approach to deliver lectures in large "in-line" classrooms, practical training in the group with the number of students from 20 to 30 is unacceptable for today's students, who prefer to transfer part of their studying home, where they have opportunity to be concentrated on training. Personal communication with peers, coeducation is important to them, but now the opportunity to work in a small group in separate convenient space is at the forefront requirement. Large spaces for training large number of students lose popularity faster [11-13]. Thus, the education in advanced countries moves towards individualization of learning in higher education, active use of scientific and educational IP-based networks, distance learning technologies allow geographically remote from one to another students work together to solve the task. The emergence of online educational resources with free access (e.g., Massive open online courses and Small private online courses) changed forever the educational services market and dramatically accelerated the online education dynamics [14].

Another dominant trend in the world of higher education is to focus on the fact to interest the student, so the educational process should cultivate actual, latest knowledge, which are closely associated with the practice. The forms of carrying classes must also undergo change into the direction of discussions encouraging [15].

In modern conditions the development prospects are determined with the ability to deploy production industry 4.0 [16-18]. Employers require increased demands to the personnel: developing industrial enterprises need young, but upscaled and experienced specialists, i.e., having not one, but two or three specialties.

\section{Results and Discussion}

To find qualified specialists companies interact with universities and open the specialized Chairs. The specialized Chairs are departments of universities, organized at the initiative of the enterprise or organization on the territory of the latter. In order to improve the quality of training university education programs should be developed in cooperation with enterprises and organizations, provided that they will order a full training group. For a successful career each student is to find his way to his liking. Professional qualities of a man are determined with his inborn psychological type, strengths and weaknesses of the individual.

Students in higher education institutions can be divided into four groups depending on the degree of motivation to the development of the educational program. The task of the university as a whole, and in particular the graduate Chair is to provide an individual approach to each student. 
First. The student is not satisfied with the choice of specialty and does not foresee his career, he receives low scores in training, does not attempt to find a job, he negatively predicts the possibility of successful employment, has no plans to continue his education, he does not monitor the situation on the labor market for the acquired profession. In this case, the Chair shall provide assistance in carrying out events for student career guidance.

Second. The student has an average rating of satisfaction with career choice, he does not attempt to find a job in an organization or independently employs in poorly satisfying his value preferences when choosing a job, desire for professional growth is limited, he gets an average score in training, does not monitor the situation on the labor market for the acquired profession. In this case, the Chair should conduct activities aimed at the awakening of interest in professional activities, facilitating a practical training period for an employer who is able to arise interest in professional self-realization.

Third. The student is satisfied with the choice of profession, has no intention of changing it, has plans for further professional growth, but very carefully simulates career move, shows high performance in the educational program, executive, he does not work during training and does not attempt to find a job. The Chair can help the student with skills of self-presentation, developing relationships through active methods, assisting in developing search work technology.

Fourth. The student is satisfied with the choice of profession, he is aimed at the acquisition of professional experience in the training period, he uses various employment possibilities, the dominant factor in the choice of employment is professional growth and opportunity for career advancement, he is characterized with medium or high performance during training, he is active in the acquisition of knowledge and participation in conferences, discussions, he has assured intentions for career advancement, he sets ambitious goals. In this case, the Chair is to motivate the students to continue their education in master and postgraduate studies, to maintain active links with the Chair, to prevent the young specialist professional "burnout".

To develop the skills of self-presentation and self-study to improve the competitiveness in the labor market, we recommend carrying out professional training to students starting from the first course. Students should be explained how to position themselves in the job market, how to set career goals and how to develop a plan to achieve those goals. Various trainings should be developed. For example:

Professional training "How to find a job in the crisis." Visiting it, students learn how to find their dream job, to diagnose a career crisis, where to look for job, how to move on to another industry due to changes in the labor market and how to overcome the risks of this switchover, how to prepare a CV and a cover letter, be interviewed, get increase in wages and positions. Questions for a career move into another city and how to do it as efficiently as possible are determined. General aspects of the economic crisis, including its stages, changes in the labor market will be covered.

Professional training "How to find a good job," will consist of two parts. The following issues will be discussed in the first part:

- Assessment of the situation in the labor market; opportunities in the crisis period.

- Evaluation of opportunities, resources of training participants as "players" in the labor market (students learn to formulate and express their personal strengths as competitive advantage in the job search).

- Setting goals when looking for work; the main stages of the search (students learn to develop personal job search strategy).

- Work with the sources of information about vacancies; non-standard ways of finding work. 
- Communication with the employer by phone (development of the first contact - the ability to make an impression on the phone and to interest, students learn to negotiate with the employer and analyze vacancy announcements).

The second part will include:

- CV preparation, the types and styles of CVs; good and bad CVs; mistakes in $\mathrm{CV}$ writing; $\mathrm{CV}$ analysis; making a $\mathrm{CV}$ and a cover letter for a particular position.

- Interviews; preparation for the interview with the employer; why people are afraid of interviews; rules of conduct at the interview; dress code; types of interviews; the most frequently asked questions of the employer (the students learn to respond to the employer's questions, learn to ask questions to the employer).

- Workshop on the passing the interview by the training participants: the story of their experience (students learn to talk about their professional experience in a positive way).

Since the beginning of the global economic crisis 2008, all countries are faced with ever new problematic issues, one of which is employment, so to help the youth in a successful career start is necessary to search for new approaches.

To solve the problem of cooperation between universities and employers information system "Personnel reserve" on the basis of the University official web-portal can be developed. The new information system will allow students to present their achievements, skills, knowledge and professional experience. Employers will be able to select independently successful graduates and young professionals for internships, training and, of course, employment. The information system will be open, i.e., each student will be able to browse the portfolio of his classmates, fellow students, etc. There will be such sections as "Jobseeker", "Employer", "Student achievements", "Partner Company", "Monitoring of employment."

In the "Jobseeker" section students can put their CVs and see the current vacancies as in the region of residence, as in other regions.

In the "Employer" section the employer will be able to create an individual request according to certain criteria and have a list of potential candidates that meet the stated requirements.

In the "Student achievements" section we will trace the development trajectory of students in extra-curricular, scientific, social, sporting life. There will be a portfolio of both as students as each university department. Clicking on the link of the department the portfolio of all enrolled students and graduates can be viewed as well as the rating of the most successful students. Each student's portfolio will provide information about work experience, participation in contests and competitions, the level of PC skills, foreign languages, participation in social life, obtained diplomas and certificates, GPA, theme and evaluation of the final qualifying work.

In the "Partner Companies" section there is a list of companies which cooperate with the university.

In the "Employment Monitoring" section there is information about the number of students and in what areas and specialties University graduates; graduates of what specialties were employed at the end of training. There will be also an opportunity to see the migration situation movement of university graduates.

The "Personnel reserve" information system is not limited to the CV bank of students and graduates, but will provide students with opportunities in their positioning in the labor market. The database will collect information on the students competencies, obtained in the course of training and in the future. After evaluating these criteria, the employer may invite students/graduates for practical training session, training, interview. To ensure the monitoring of incoming information from the students portfolio materials of graduate Chair should be loaded, as well as the introduction of an internal exam to determine the level of foreign language knowledge with the results publication in the information system. 


\section{Conclusions}

The "Personnel reserve" information system will increase the motivation of students to treat study, work, and self-actualization more seriously. Fair competition will be developed between the students who will be interested to collect as many achievements on their CVs, to attract the employer. Due to it, students will use all various resources of the University and graduate with the modern highly qualified level, possessing complementary skills. Each student will get a perfect opportunity to assert himself on the labor market with a simple and effective way - to locate his individual portfolio on the virtual site.

The possibility of students' feedback and especially university graduates is to be provided. To this end, the development of an information system should be conducted from the perspective of creating inter university local social network, its members will be not only the students and alumni, but staff and even to broaden participation by future students - it will strengthen the capabilities of the University in attracting talented and promising youth. Thus, as a result of self-presentation and self-employment training, the development of "Personnel reserve" information system, the students interest to the complete mastering of the educational program, active participation in extra-curricular, scientific and sports activities will increase and that allows students to prove them the best in the labor market. The implementation of the proposed events will improve the status and recognition of the university at the regional and international level. The final result will be the graduation of versatile educated professionals who will be in demand in the modern industrial productions, will be capable of generating new ideas, modernization of production processes, which will increase the sustainability of economic development of separate regions and entire countries, increase their competitiveness in the global economy.

\section{References}

1. P. Courtioux, V. Lignon, Economic Modelling 57, 221 (2016)

2. Castillo, Journal of Cleaner Production 143, 180 (2017)

3. Ch. Featherston, E. O'Sullivan, Technological Forecasting and Social Change 115, 261 (2017)

4. F. Huang et al, Journal of the Energy Institute (2016)

5. M. Akçayır et al, Computers in Human Behavior 57, 334 (2016)

6. H.B. Congdon, Journal of Interprofessional Education \& Practice 5, 53 (2016)

7. J. Hemsley-Brown et al, Journal of Business Research 69, 3019 (2016)

8. C. Piewa et al, Journal of Business Research 69, 3087 (2016)

9. Ch. Dennis et al, Journal of Business Research 69, 3049 (2016)

10. W.L. Filho, C. Shiel, A. Paço, Journal of Cleaner Production 133, 126 (2016)

11. R. Beckers, T. Voordt, G. Dewull, Building and Environment 104, 243 (2016)

12. N.M. Natalinova et al, Proc. of EpSBS XIX, 476 (2017)

13. Trappey et al, Advanced Engineering Informatics, (2016)

14. Th.D. Oesterreich, F. Teuteberg, Computers in Industry 83, 121 (2016)

15. E. Shutenko, A. Shutenko, Procedia - Social and Behavioral Sciences 214, 332 (2015)

16. L. Huo, N. Song, Physica A: Statistical Mechanics and its Applications 461, 73 (2016)

17. J. Stoutenborough, A. Vedlitz, Energy Policy 96, 206 (2016)

18. Y.-S. Changetal, Computers in Human Behavior, 63, 988 (2016) 